\title{
Recent advances in the understanding of the molecular mechanisms regulating platelet integrin allb $\beta 3$ activation
}

\author{
Lanlan Tao ${ }^{1,2}$, Yue Zhang ${ }^{1}$, Xiaodong $\mathrm{Xi}^{1,2}$, Nelly Kieffer ${ }^{1 凶}$ \\ ${ }^{1}$ Sino-French Research Center for Life Sciences and Genomics (CNRS/LIA-124), Ruijin Hospital, Shanghai Jiaotong University \\ School of Medicine, Shanghai 200025, China \\ 2 State Key Laboratory of Medical Genomics and Shanghai Institute of Hematology, Ruijin Hospital, Shanghai Jiaotong \\ University School of Medicine, Shanghai 200025, China \\ $\bowtie$ Correspondence: nkieffer@pt.lu \\ Received June 19, 2010 Accepted June 24, 2010
}

\begin{abstract}
Integrins are allosteric cell adhesion receptors that cycle from a low to a high affinity ligand binding state, a complex process of receptor activation that is of particular importance in blood cells such as platelets or leukocytes. Here we highlight recent progress in the understanding of the molecular pathways that regulate integrin activation in platelets and leukocytes, with a special focus on the structural changes in platelet integrin $\alpha$ llb $\beta 3$ brought about by key intracellular proteins, namely talin and kindlins, that are of crucial importance in the regulation of integrin function. Evidence that the small GTPase Rap1 and its guanine exchange factor CaIDAG-GEF1, together with RIAM, a Rap1GTP adaptor protein, promote the interaction of talin with the integrin $\beta$ subunit, has greatly contributed to fill the gap in our understanding of the signaling pathway from G-coupled agonist receptors and their phospholipase $\mathrm{C}$-dependant second messengers, to integrin activation. Studies of patients with the rare blood cell disorder LAD-III have contributed to the identification of kindlins as new co-regulators of the talin-dependent integrin activation process in platelets and leukocytes, underlining the relevance for the in-depth investigation of patients with rare genetic blood cell disorders.
\end{abstract}

\section{INTRODUCTION}

Blood cells in the vasculature are constantly exposed to hemodynamic forces generated by the flow of blood, and rely largely on adhesion receptors such as integrins to counteract these dispersive forces and to allow anchorage-dependent cell events. Integrins represent a large family of heterodimeric transmembrane adhesion receptors that are formed by the non-covalent association of various $\alpha$ and $\beta$ subunits. $A$ hallmark of integrins is their ability to promote bidirectional signaling across the cell membrane (Hynes, 2002). For example, endothelial cells of the vaculature use integrins to interact with the extracellular matrix (ECM) of the subendothelium, and engaged integrins transduce signals (outsidein signaling) that are critical for the dynamic regulation of endothelial cell functions such as adhesion, migration and proliferation (Harburger and Calderwood, 2009). Circulating blood cells on the other hand switch from nonadherent to adherent cells as a result of integrin activation (inside-out signaling) leading to platelet aggregation during hemostasis, leukocyte attachment to the vessel wall and extravasation to surrounding tissues during inflammation, or immune $B$ and $T$ cell interactions in immunological synapses (Abram and Lowell, 2009). In platelets, integrin $\alpha$ llb $\beta 3$ serves as a receptor for platelet adhesion to the exposed ECM, and additionally functions as a fibrinogen receptor that mediates platelet aggregation through binding of plasma fibrinogen, two platelet functions that are essential for sealing injured blood vessels and preventing blood loss. Indeed, genetic defects in functional integrin allb $\beta 3$ expression in the megakaryocytic/ platelet lineage are the cause of a severe bleeding disorder, Glanzmann's thrombasthenia (GT) characterized by defective platelet aggregation (Nurden, 2006). In contrast, excessive platelet aggregation can initiate arterial thrombosis, causing heart attacks and stroke. To ensure that platelets, which are constantly exposed to plasma fibrinogen in the circulating blood, only aggregate at sites of vessel injury, 
platelet integrins exist in a low-affinity ligand binding state and shift to a high-affinity state following platelet stimulation by various agonists, such as ADP or thrombin, compounds that are released into the blood stream at sites of vessel injury (Savage et al., 1998). In platelets, this switch in allb $\beta 3$ ligand binding affinity is commonly referred to as allb $\beta 3$ activation or integrin inside-out signaling (Hynes, 2002). Similarly, circulating leukocytes maintain their $\beta 2$ integrins in a nonadhesive state; however, at sites of inflammation or infection, released chemoattractants and cytokines induce $\beta 2$ integrin activation allowing the firm arrest of leukocytes on the inflamed endothelium and transmigration through the subendothelium to allow leukocyte homing to sites of inflammation or infection. The physiologic importance of $\beta 2$ integrin-dependent blood cell adhesion is underlined in patients with genetic defects in leukocyte $\beta 2$ integrin expression (LAD, leukocyte adhesion deficiency), who suffer from recurrent life-threatening bacterial infections (Abram and Lowell, 2009).

\section{CHO CELLS AS A MODEL TO INVESTIGATE RECOMBINANT INTEGRIN allbB3 FUNCTION}

Much of the progress achieved in integrin allb $\beta 3$ research has been obtained following investigation of wild type or mutant integrin allb $\beta 3$ receptors expressed in Chinese hamster ovary $(\mathrm{CHO})$ cells, used as putative surrogates for anucleated platelets that cannot be genetically manipulated. It has to be mentioned, however, that in these cells, integrin allbß3 is in a constitutive low affinity ligand binding state, unable to interact with soluble fibrinogen, but can be artificially activated to bind this ligand either by activating monoclonal antibodies, or by $\mathrm{Mn}^{2+}$ that binds to the integrin head $\mathrm{A}$ domain and induces the high affinity ligand binding conformation. Over the years, monitoring of integrin allb $\beta 3$ activation has been performed with a monoclonal antibody PAC-1, which does not bind to allb $\beta 3$ in resting platelets, but interacts with allb $\beta 3$ following thrombin stimulation of platelets, and is therefore largely used as a ligand mimetic (Shattil et al., 1987). Although this multivalent IgM antibody has recently been shown to monitor integrin allb $\beta 3$ affinity/clustering, i.e., integrin avidity rather than affinity (Bunch, 2010), for convenience, we will continue to refer to this antibody as a marker of integrin allb $\beta 3$ activation.

\section{STRUCTURAL CHANGES IN INTEGRIN $\alpha$ Ilbß33 DURING ACTIVATION}

A key contribution to the understanding of integrin allb $\beta 3$ activation was the initial observation that mutation of the highly conserved $D^{723}$ residue in the membrane proximal part of the $\beta 3$ subunit cytoplasmic tail or the equivalent $R^{995}$ residue in the a subunit membrane proximal part was sufficient to activate integrin allbß3 (Hughes et al., 1996), suggesting that a salt bridge between $\beta 3 \mathrm{D}^{723}$ and allbR ${ }^{995}$ keeps the two cytoplasmic tails in close contact and stabilizes integrins in their low affinity state.

The $\beta 3 D^{723}$ and allbR ${ }^{995}$ residues are located in two highly conserved sequences in the membrane proximal part of the $\alpha$ (GFFKR) and the $\beta$ subunits (HDR(R/K)E), reported to form $\alpha-$ helical coiled-coiled interactions (Vinogradova et al., 2002). Deletion or mutations of these sequences leads to integrin activation both in vitro and in vivo (Luo et al., 2007). However, the notion of helical coiled-coiled interactions between the $\alpha$ and $\beta$ subunits in the transmembrane domain and the membrane-proximal cytoplasmic part has recently been challenged by two independent reports (Lau et al., 2009; Zhu et al., 2009), which revealed an unusual asymmetric structure of the transmembrane $\alpha$ and $\beta$ subunit helixes that span the membrane at an angle of $25^{\circ}$ due to their unequal length. While the $\beta 3$ transmembrane helix extends into the cytoplasm, the $\alpha$ helix is interrupted at the cytoplasmic face of the membrane by a $\mathrm{G}$ cap structure of the GFFKR sequence, with the two FF residues partially embedded into the hydrophobic portion of the membrane bilayer into the interface with the $\beta 3$ subunit. This unusual non-helical structure of the allb subunit does however not preclude the formation of the ionic salt bridge between residue $\mathrm{R}^{995}$ of allb and residue $D^{723}$ of $\beta 3$ cytoplasmic tails, known to be important to keep integrins in the low affinity state (Kim et al., 2009).

On the basis of structural studies, it has been suggested that integrins in their low affinity state have a bent, v-shape conformation with the head piece oriented toward the cell membrane, while the ligand binding high affinity receptor adopts an extended upright conformation, that would roughly double its molecular height to about $200 \AA$ (Xiong et al., 2001). Also, in vitro and in vivo data suggest that in the bent conformation, the subunit transmembrane and cytoplasmic domains are in close contact, while they are separated in the high affinity conformation (Kim et al., 2009).

Integrins can adopt different stages of ligand binding affinity and to date, it is still unclear whether ligand binding only occurs to the extended conformation. Indeed, two models have been proposed, (a) the switchblade model which predicts that only extended integrins will bind ligand (Luo et al., 2007), whereas (b) the deadbolt model (Xiong et al., 2003) suggests that ligand binding occurs to the bent integrin and that extension occurs only following ligand binding. In vitro integrin activation by $\mathrm{Mn}^{2+}$ only alters the cation coordination in the integrin A domain (Shimaoka et al., 2002) and does not promote separation of the cytoplasmic tails (Kim et al., 2009), a mechanism thought to be indispensable for integrin extension.

\section{ROLE OF CYTOPLASMIC PROTEIN TALIN IN INTEGRIN allbß3 ACTIVATION}

For many years, the biochemical pathways that take place in platelets and link agonist receptor signaling to integrin allb $\beta 3$ 

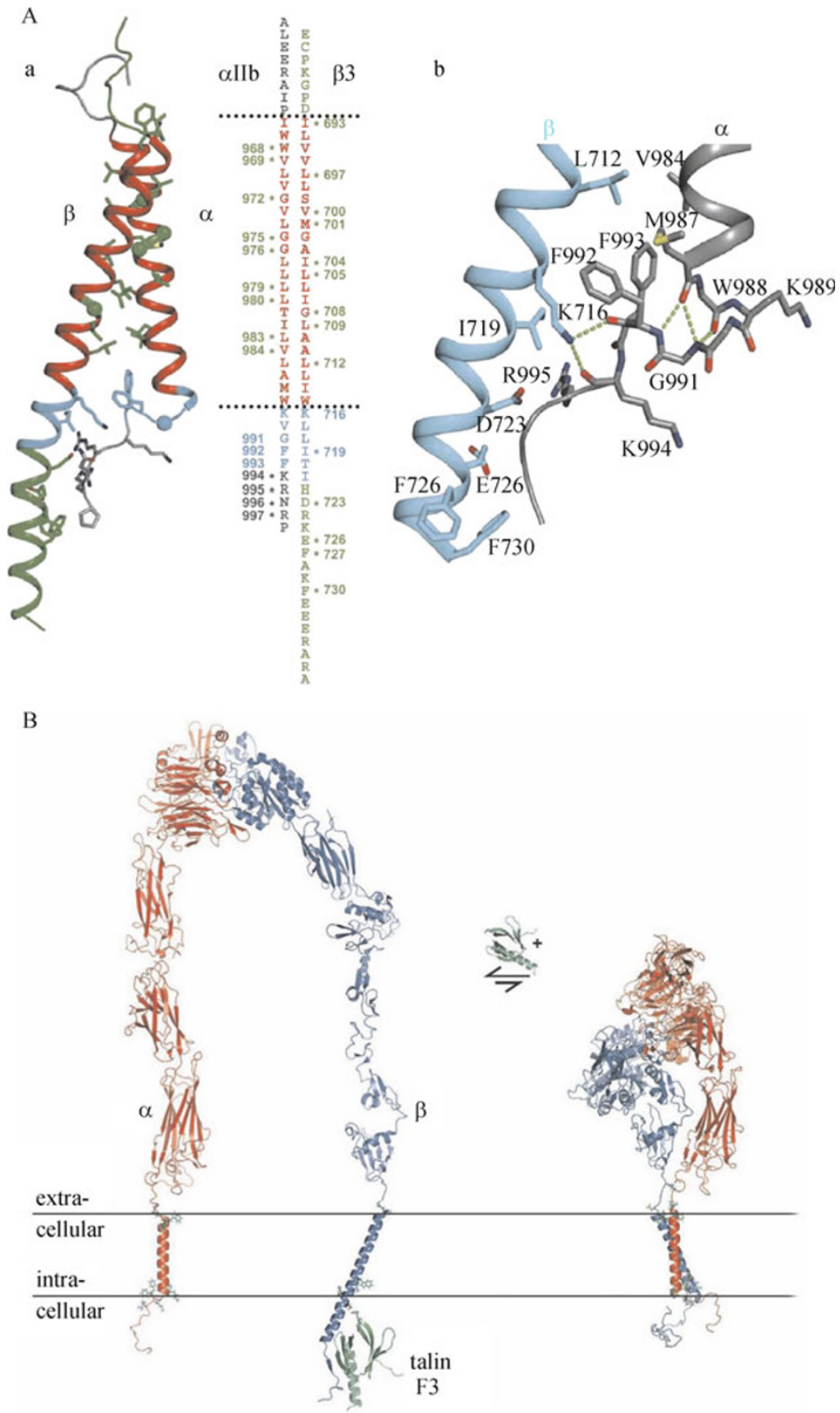

Figure 1. Structural models of integrin allbß3. (A) (a) Amino acid sequence and structure of the transmembrane (red), juxtamembrane (blue) and cytoplasmic segments (green) of integrin allbß3 in its inactive conformation. (b) Enlarged view of the juxtamembrane domain showing the inter-subunit amino acid contacts: hydrogen bonds are dashed green lines; nitrogens, oxygens, and sulfurs are blue, red and yellow, respectively. (from Zhu et al., 2009). (B) Structural model illustrating integrin allb $\beta 3$ inside-out activation by the talin head F3 domain according to Lau et al. (2009). Prior to talin binding, integrin allbß3 adopts a bent, v-shaped conformation stabilized in the juxtamembrane domain by inter-subunit ionic bonds. The talin F3 domain interaction with the integrin $\beta 3$ subunit cytoplasmic tail disrupts the ionic bond $\alpha \mathrm{llbR}{ }^{995}-\beta 3 \mathrm{D}^{723}$ and promotes separation of the 2 subunits with long range conformational changes in the extracellular domain necessary for the induction of the extended conformation.

activation have remained elusive. It was therefore quite surprising when the cytoskeletal protein talin, known to link integrin $\beta$ subunit cytoplasmic tails to the actin cytoskeleton, was identified as the final effector of integrin activation (Tadokoro et al., 2003). Talin is a 270-kDa cytoplasmic protein, which can be cleaved by calpain into a globular head 
domain and a rod like tail domain. Although both the talin head and the talin rod domain contain an integrin binding site, it is the talin head interaction with the integrin $\beta$ subunit cytoplasmic tail that activates integrins (Calderwood et al., 1999). The talin head contains a FERM (band 4.1/ezrin/ radixin/moesin) homology domain, composed of 3 subdomains F1-F3, with a phosphotyrtosine binding (PTB)-like fold in the $\mathrm{F} 3$ subdomain. By solely overexpressing the talin head F3 subdomain in the $\mathrm{CHO}$ cell model, Calderwood et al. were able to induce mAb PAC-1 binding to integrin allb 33 .

The talin head-integrin contact site was mapped to the $\beta 3$ cytoplasmic tail NPXY ${ }^{747}$ sequence, a typical binding motif for proteins with a PTB domain and highly conserved in integrin $\beta$ subunits. Also, mutation of the $Y^{747}$ residue or the upstream $\mathrm{W}^{739}$ residue was sufficient to disrupt this interaction (Calderwood et al., 2002; Calderwood and Ginsberg, 2003; GarcíaAlvarez et al., 2003). Interestingly however, other PTBdomain containing proteins known to interact with the NPXY motif of integrins, such as Dok1, tensin or Numb, were unable to induce integrin activation. Recent structural data of the F3 domain of talin 1 in complex with the $\beta 3$ cytoplasmic tail (Wegener et al., 2007) or the F2-F3 subdomains of talin2 in complex with the integrin $\beta 1 \mathrm{D}$ cytoplasmic tail have provided a possible explanation for this observation by revealing additional talin head contact sites in the $\beta$ subunit, upstream of the NPXY ${ }^{747}$ motif, and located in the $\beta$ subunit membrane proximal $\alpha$-helix. In particular, a loop in the talin F3 domain that does not exist in Dok1, tension or Numb, establishes contacts with $2 \mathrm{~F}$ residues, $\mathrm{F}^{727}$ and $\mathrm{F}^{730}$ (Wegener et al., 2007), while a $K$ residue in this loop engages with the $\beta 1 D$ subunit $D$ residue, known to form a salt bridge with the $\alpha$ subunit, thus providing the clue on how talin head, by binding to the integrin $\beta$ subunit, can break this salt bridge and activate integrins (Anthis et al., 2009).

Additional basic residues in the $\mathrm{F} 2$ and $\mathrm{F} 3$ domains engage with acidic phospholipids of the cell membrane (Anthis et al.,
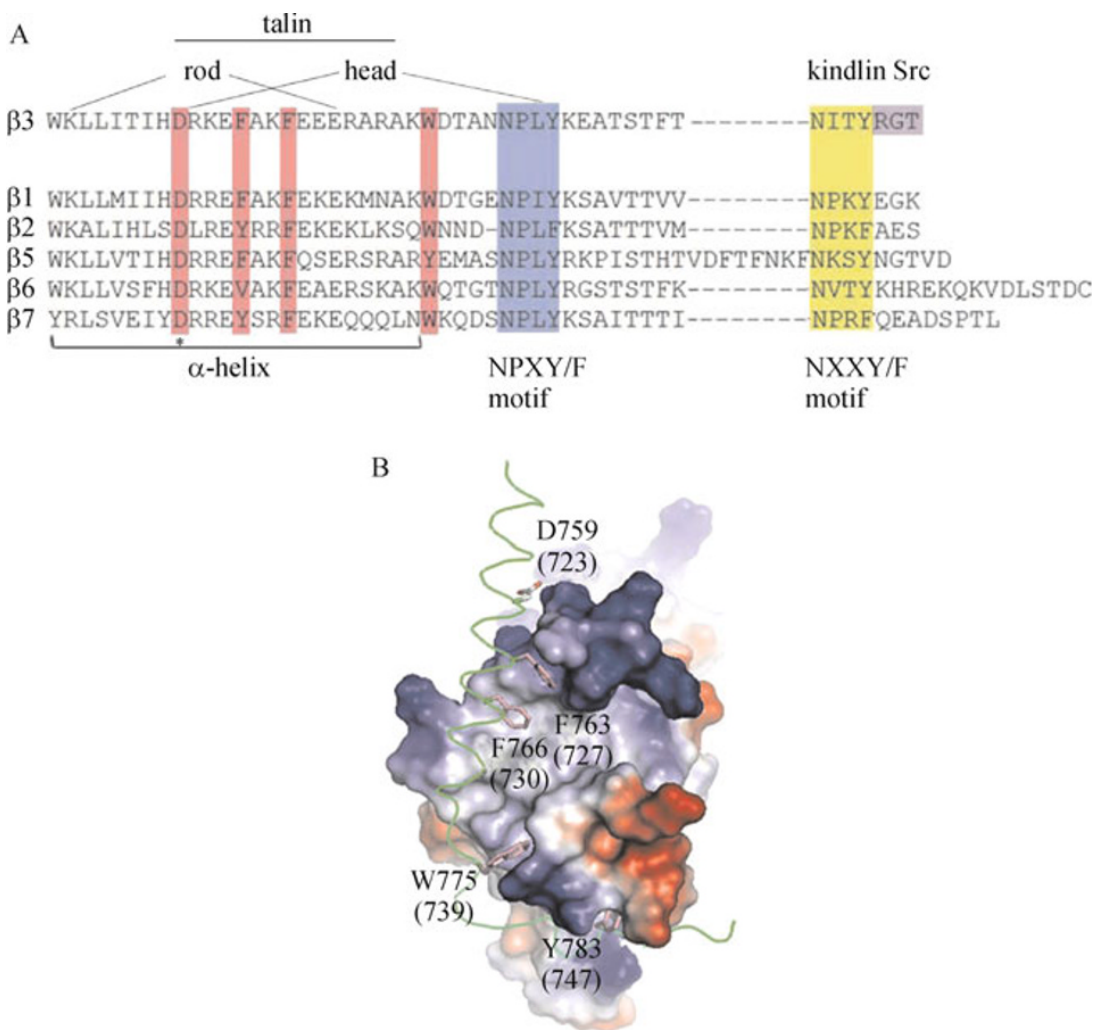

Figure 2. Sequence alignment of integrin $\beta$ subunits and binding model of talin head-integrin tail. The highly conserved PTB protein binding motifs NPXY/F and NXXY/F are shown in blue and yellow, respectively. The Src 'RGT' binding site in $\beta 3$ is shown in purple. Residues of the membrane proximal $\alpha$ helix involved in talin head binding are shown in pink. The $D$ residue that establishes an ionic salt bridge with integrin $\alpha$ subunits is marked with an asterisk. The overlapping talin head and talin rod binding domains are indicated. (B) Crystal structure of talin2 F2-F3 domain bound to the $\beta 1 \mathrm{D}$ integrin tail (in green). Residues in the integrin $\beta 1 \mathrm{D}$ subunit shown to be important for talin binding are highlighted ( $\beta 3$ residue numbering is indicated in parenthesis). Acidic residues in talin are shown in red and basic residues in blue. (from Anthis et al., 2009). 
2009; Saltel et al., 2009) and reorient the talin head together with the integrin $\beta$ subunit, promoting the separation of the transmembrane helices of the integrin $\alpha$ and $\beta$ subunits. It has to be mentioned that only the non-phosphorylated NPXY ${ }^{747}$ motif in the integrin $\beta$ subunit can associate with the PTB-like F3 domain of the talin head, suggesting that phosphorylation of $Y^{747}$ in $\beta 3$ negatively regulates talin binding and integrin activation (Anthis et al., 2009). And finally, recent data have shown that talin head binding to a single integrin allb $\beta 3$ molecule inserted into a phospholipid layer is sufficient to induce the long-range conformational change that converts allbß3 from a bent to an extended receptor (Ye et al., 2010).

How then do agonists, which stimulate platelets and promote integrin activation, induce the translocation of talin from the cytosol to the platelet membrane? Agonist regulated redistribution of platelet talin from the cytosol to the inner face of the platelet membrane was initially reported in thrombinand glass-activated, substratum-adherent platelets (Beckerle et al., 1989). Also, agonist-induced activation of allbß3 in platelets has been known for years to be dependent on the generation of $\mathrm{Ca}^{2+}$ and diacylglycerol (DAG). These second messengers are generated by phospholipase $\mathrm{C}$ downstream of platelet agonist receptors such as the thrombin receptor (PAR) or the ADP receptor (P2Y1), two members of the G protein coupled receptor family (GPCRs) (Rivera et al., 2009). Research in the leukocyte field had already identified the guanosine triphosphatases (GTPases) Rap1 and Rap2 as important effectors downstream of PKC in integrin activation in thymocytes and neutrophiles. Also, through genetic ablation in mice of the guanine exchange factor CalDAGGEF1, that, similar to PKC, binds $\mathrm{Ca}^{2+}$ and DAG and regulates the GDP-GTP cycle of Rap1, it was shown that CalDAG-GEF1 is involved in an additional signaling pathway that links platelet agonist receptors to integrin activation, as platelets from these mice failed to aggregate (Crittenden et al., 2004; Bergmeier et al., 2007). The final missing link between activated Rap1 and talin-dependent integrin activation was however established by Ginsberg's group who used the $\mathrm{CHO}$ cell model to reconstitute the entire signaling pathway mimicking integrin allb $\beta 3$ activation in human platelets. They first demonstrated that the low expression levels of talin and PKC $\alpha$ in $\mathrm{CHO}$ cells were responsible for the inability of integrin allb $\beta 3$ to become activated in these cells (Han et al., 2006). Next, by stimulating $\mathrm{CHO}$ cells (overexpressing talin and $\mathrm{PKC} \alpha$ ) with phorbol 12-myristate 13acetate (PMA), which triggers PLC activation and the formation of IP3 and DAG, they showed that Rap1 activates integrins by forming a complex with talin and RIAM, a Rap1GTP-interacting adaptor molecule. A similar integrin allb $\beta 3$ activation in $\mathrm{CHO}$ cells was also achieved following overexpression of the thrombin receptor (Watanabe et al., 2008). More recently, it has been shown that activated Rap1 targets to the lipid membrane following farsenylation of its CAAX motif, while RIAM functions as a linker and binds to both talin and Rap1, thereby recruiting talin to the plasma membrane for its interaction with integrins. Interestingly, overexpression of an artificial fusion protein composed of the CAAX motif of Rap1 (10 residues) and the talin binding motif of RIAM (30 residues) is sufficient to promote integrin activation (Lee et al., 2009).

\section{ROLE OF TALIN IN LINKING INTEGRINS TO THE CYTOSKELETON}

Although talin functions as the final effector in integrin activation, it was initially identified as a cytoskeletal protein that links integrins to the actin cytoskeleton (Horwitz et al., 1986). Interaction of homo-dimerized talin with integrins is thought to promote the lateral mobility and clustering of integrins within the plane of the plasma membrane, and to recruit additional cytoplasmic proteins, such as vinculin and actin, to form transient self-assembling complexes, called focal contacts (FC), that eventually mature into focal adhesions (FA) (Critchley, 2009). FAs function as integrinrich signaling hubs, which promote strong contacts with the surrounding matrix, link integrins to the actin cytoskeleton and orchestrate outside-in signaling pathways by recruiting a large number of cytoskeletal, adaptor and signaling proteins (Geiger et al., 2009). Some of these signaling proteins, namely p125FAK (focal adhesion kinase), Src and ILK (integrin linked kinase), have been reported to directly associate with integrin $\beta$ subunit cytoplasmic tails. Src binding however only occurs to $\beta 3$ among integrin $\beta$ subunits and targets its last three $\mathrm{C}$-terminal residues, RGT (Arias-Salgado et al., 2003). Interestingly, a membrane permeable RGT peptide has recently been shown to inhibit integrin allb $\beta 3$ outside-in signaling in platelets without affecting integrin activation (Su et al., 2008).

Using the drosophila model, Tanentzapf et al. were the first to show that the talin head and talin rod serve different functions, as interaction between integrin and the talin FERM domain mediates integrin activation but does not promote linkage to the cytoskeleton, thus underlining the importance of the additional integrin binding site in the talin rod domain (Tanentzapf and Brown, 2006). The talin rod is composed of 62 a-helices organized into a series of four or five-helix bundles followed by a single C-terminal helix that allows talin dimerization. A number of these helical bundles are involved in protein-protein interactions and function as binding sites for vinculin (VBS1, 2, 3), actin (ABS2) and integrins (IBS2) (Critchley, 2009). The second integrin binding site (IBS2) in the talin rod domain appears to play a major role in integrin outside-in signaling, as expression in mouse talin $1(-/-)$ cells of a full-length mouse talin with the IBS2 binding site inactivated by a LI/AA mutation, was unable to rescue the inability of these cells to assemble focal adhesions (Tremuth et al., 2004; Moes et al., 2007). Within IBS2, talin rod helix 50 has been shown in vitro to establish direct contacts with the 
membrane proximal $\alpha$ helix of $\beta 3$ and $\beta 1$ integrins (Rodius et al., 2008; Gingras et al., 2009), based on charge complementary ionic bonds. As the talin head and talin rod contact sites in the integrin membrane proximal domain are in close proximity and partially overlapping, it remains to be determined whether talin head and talin rod binding to the integrin $\beta$ subunits is simultaneous or sequential.

\section{FUCTIONAL ROLE OF KINDLINS IN INTEGRIN ACTIVATION AND OUTSIDE-IN SIGNALING}

Over the recent years, talin has evolved as a major activator of integrin ligand binding function. However, experimental data have suggested the existence of additional co-activators, as talin head binding to the integrin cytoplasmic tail in the $\mathrm{CHO}$ cell model was unable to achieve the same level of integrin activation as that measured following $\mathrm{Mn}^{2+}$ binding or antibody activation (Ma et al., 2007; Bouaouina et al., 2008). Among the numerous proteins known to interact with integrin cytoplasmic tails, kindlins have recently emerged as new coregulators of integrin activation.

The kindlin family consists of three members (kindlin- $1,-2$, -3) that are encoded by 3 separate genes and are expressed in a tissue- or cell type-specific manner. Kindlin-1 is ubiquitously expressed in murine and human tissues, including skin, heart, lung, liver, kidney, colon, prostate, ovary and pancreas (Siegel et al., 2003). Kindlin-2 is also expressed ubiquitously with the exception of hematopoietic cells and it is the only kindlin expressed in embryonic stem (ES) cells (Ussar et al., 2006; Dowling et al., 2008). In contrast, kindlin-3 is restricted to hematopoietic cells where it is particularly abundant in megakaryocytes and platelets (Ussar et al., 2006). Within the cells, all 3 kindlins have a similar subcellular distribution, as they colocalize with integrins in adhesion structures, suggesting that they have very similar functions (Tu et al., 2003; Weinstein et al., 2003). However, certain kindlins are also found to localize to unique structures, e.g., kindlin-2 is present in cell-cell contacts or in the nucleus, indicating exclusive functions of some of the kindlin family members (Ussar et al., 2006). The three mammalian kindlins, kindlin-1 (also known as kindlerin and FERMT1), kindlin-2 (MIG-2) and kindlin-3 (URP2) exhibit high sequence similarities with identical domain architecture (Larjava et al., 2008). Kindlins contain a C-terminally located FERM domain which is divided into three subdomains F1, F2, F3. A structural hallmark of kindlins is the interruption of the F2 subdomain by a pleckstrin homology $(\mathrm{PH})$ domain, suggesting that these proteins can be recruited to the cell membrane by binding to phosphoinositides (Weinstein et al., 2003; Larjava et al., 2008). In comparison to other FERMdomain containing proteins, the F3 subdomain of kindlins shares the highest homology with the talin F3 domain (Kloeker et al., 2004). Also, in vitro binding studies using recombinant proteins have shown that the F3 subdomain of

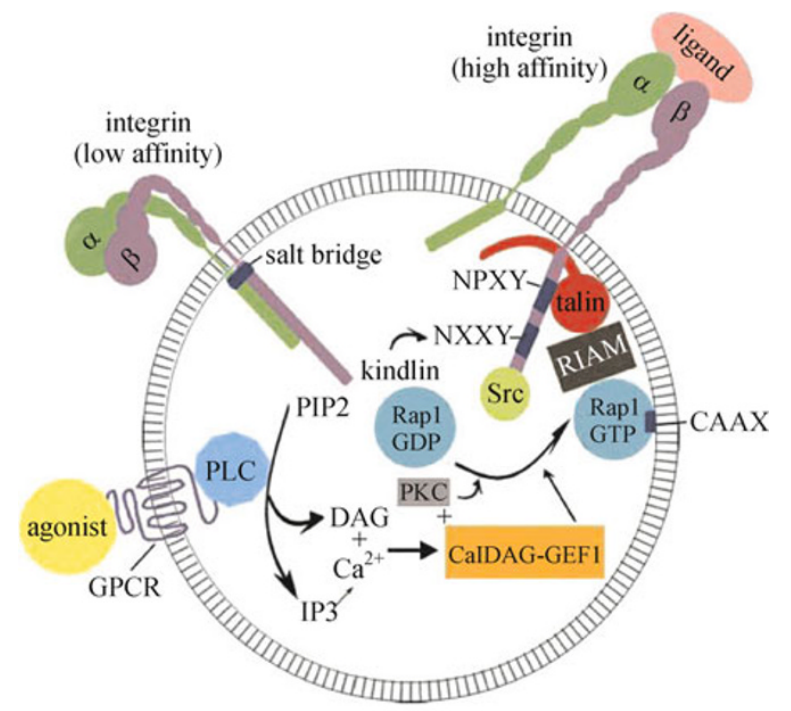

Figure 3. Schematic drawing of the signaling cascade that leads to integrin activation in platelets. Agonist stimulation of $G$ protein coupled receptors (GPCR) triggers PLC activation and the formation of IP3 and DAG. DAG and $\mathrm{Ca}^{2+}$, the latter being released by IP3, activate CaIDAG-GEF1 and PKC. Activated CalDAG-GEF1 along with PKC leads to the shift of Rap-1GDP to Rap-1GTP. Rap-1GTP targets to the lipid membrane following farsenylation of its CAAX motif. RIAM, a RAP-1GTP interacting adaptor protein, functions as a linker and binds to both the talin head and Rap-1 to form a complex, thereby recruiting talin to the plasma membrane for its interaction with the intergrin $\beta$ subunit. Talin head binding to the conserved NPLY motif disrupts the salt bridge between the $\alpha$ and $\beta$ subunits and promotes integrin activation with a shift from a bent to an extended, ligand binding conformation. Kindlin binding to the NXXY motif and Src binding to the Cterminal RGT motif is shown.

kindlins can interact directly with integrin $\beta$ subunit cytoplasmic tails. All three kindlins interact with $\beta 1$ and $\beta 3$ integrin tails, while kindlin- 3 additionally binds to $\beta 2$ (Larjava et al., 2008; Montanez et al., 2008; Harburger et al., 2009; Moser et al., 2009).

An initial hint on the functional role of kindlins came from studies in the nematode Caenorhabditis elegans in which the absence of the unique kindlin gene product, UNC-112, induced the PAT phenotype, characterized by defective worm motility (Rogalski et al., 2000). In addition, in wild type animals, UNC-112 was shown to co-localize with PAT-3, the C.elegans unique integrin $\beta$ subunit, and to be essential for the assembly of proper cell-matrix adhesion structures. As kindlins do not contain catalytic domains, it was suggested that they might function as adaptor proteins promoting protein-protein interactions. And indeed, in addition to the integrin cytoplasmic tails, kindlins have also been shown to interact with ILK (Mackinnon et al., 2002; Tu et al., 2003; 
Legate et al., 2006; Montanez et al., 2008) and migfilin (Tu et al., 2003; Wu, 2005), two FA proteins that directly or indirectly regulate actin dynamics and integrin-dependent intracellular signaling pathways.

Further studies using $\mathrm{CHO}$ cells stably expressing integrin allb $\beta 3$ revealed that co-expression of the talin head together with kindlin-1 or kindlin-2 resulted in enhanced allb $\beta 3$ activation, as monitored by mAb PAC-1 binding (Ma et al., 2007; Bouaouina et al., 2008; Harburger et al., 2009). This effect was dependent on a direct interaction of the kindlin FERM domain with allb $\beta 3$. Mutational analysis showed that the second conserved NXXY ${ }^{759}$ motif of the integrin $\beta 3$ tail, and a conserved tryptophane in the F3 subdomain of the kindlin FERM domain, were directly involved in kindlinintegrin interactions (Shi et al., 2007; Moser et al., 2008; Harburger et al., 2009). Thus, in contrast to the talin head domain, which interacts with the membrane proximal NPXY motif of integrin $\beta$ subunits, kindlins target the membranedistal NXXY motif of integrin $\beta$ subunits.

Another breakthrough on the functional role of kindlins came from studies of kindlin-knockout mice. Mice with a kindlin-1 gene deletion had skin as well as intestinal defects (Ussar et al., 2008), whereas knockout of the kindlin-2 gene in mice resulted in early embryonic lethality (Dowling et al., 2008; Montanez et al., 2008). Mice with the kindlin3-gene knockout only survived for about 1 week, due to severe leukocyte and platelet defects (Krüger et al., 2008; Moser et al., 2008). Kindlin-3 (-l-) mice showed normal platelet counts but severe platelet dysfunction, such as defective platelet aggregation in vitro or thrombus formation in vivo, that led to severe hemorrhages and resistance to arterial thrombosis. Although platelets from kindlin-3 (-l-) mice were able to establish initial contacts with von Willebrand factor (VWF)/collagen via the vWF receptor GPIb and the collagen receptor GPVI, they were unable to spread on these ligands as a result of defective allb $\beta 3$ and $\alpha 2 \beta 1$ integrin activation (Moser et al., 2008). Interestingly, $\mathrm{Mn}^{2+}$ treatment of kindlin-3 deficient platelets allowing artificial activation of the platelet integrins, did not restore platelet spreading, suggesting an additional functional role of kindlins in integrin outsidein signaling. On the other hand, studies using kindlin-3 (-l-) polymorphonuclear granulocytes isolated from kindlin-3 (-l-) chimeric mice showed that kindlin-3 is not required for leukocyte rolling on inflamed endothelium but is essential for their firm adhesion (Moser et al., 2009). Indeed, kindlins have been shown to cooperate with ILK by interacting with each other and to orchestrate the recruitment of other proteins, such as migfilin to FAs. However, how kindlins regulate integrin-mediated outside-in signaling is still unclear.

Kindlin deficiency in humans has further contributed to the understanding of the functional role of these proteins. The kindlin name refers to the Kindler syndrome first described by Dr. Kindler in 1954, of patients with congenital skin blistering, skin fragility and sun sensitivity, with often oral and colonic involvement (Kindler, 1954). Histological analysis of the skin blisters revealed epithelial detachment from the basal membrane, pointing to a defect in integrin function. Kindlin-2 deficiency in patients has not been reported, and is predicted to be embryonically lethal. Finally, the real breakthrough in identifying the functional role of kindlins in integrin activation came from the investigation of patients with a rare genetic blood cell disorder, called LAD-III. Patients with LAD-III suffer from Glanzmann's thrombasthenia-like bleeding problems in addition to life-threatening infections, typical of the LAD disorder which is caused by a genetic defect in $\beta 2$ integrin expression (Kuijpers et al., 2009; Svensson et al., 2009). However, LAD-III patients have normal integrin expression in their platelets and leukocytes, and their defect relates to an inability of integrins $\beta 1, \beta 2$ and $\beta 3$ to become activated in platelets, neutrophils and lymphocytes. Initially, evidence was provided that LAD-III results from a homozygous single nucleotide $\mathrm{C} \rightarrow \mathrm{A}$ splice-junction mutation in the CalDAGGEF1 gene (Kinashi et al., 2004; Pasvolsky et al., 2007) whose product is known to regulate Rap1. However, more recently, 2 independent groups have shown that mutations in the gene encoding kindlin-3 constitute the primary molecular defect in LAD-III, with all of the LAD-III patients described so far having undetectable kindlin-3 expression (Mory et al., 2008; Kuijpers et al., 2009). This observation was further confirmed by complementation studies showing that expression of kindlin-3, but not CalDAG-GEF1 in LAD-III patientderived cell lines restored their adhesive phenotype, thus underlining the role of kindlins in integrin activation. Interestingly however, some but not all of the patients also presented the $\mathrm{C} \rightarrow \mathrm{A}$ splice-junction mutation in the CaLDAG-GEF1 gene. Whether this CalDAG-GEF1 mutation is an innocuous single nucleotide polymorphism (SNP), or whether it also contributes to the LAD-III disorder is still unclear, as CaIDAGGEF1 acts upstream of Rap1 in the talin-dependent integrin activation pathway.

\section{INTEGRIN AFFINITY REGULATION IN CONSTITU- TIVELY ADHERENT CELLS}

Most information on the molecular events that lead to integrin activation have been obtained by studying platelets or leukocytes, two blood-derived cell types in which integrin activation is initiated through stimulation of agonist receptors, such as the thrombin receptor or the ADP receptor in platelets, or the chemokine receptors in leukocytes, all of which are G-coupled receptors. In contrast, integrin activation in constitutively adherent cells, such as endothelial cells or fibroblasts, appears to rely on a different pathway, since agonist receptors are not involved in this process, with integrins being the primary sensors that establish the initial cell-extracellular matrix contact. Recently, evidence has been provided that in adherent cells, integrin activiation might rely on mechanical signaling initiated by force generated tension. 


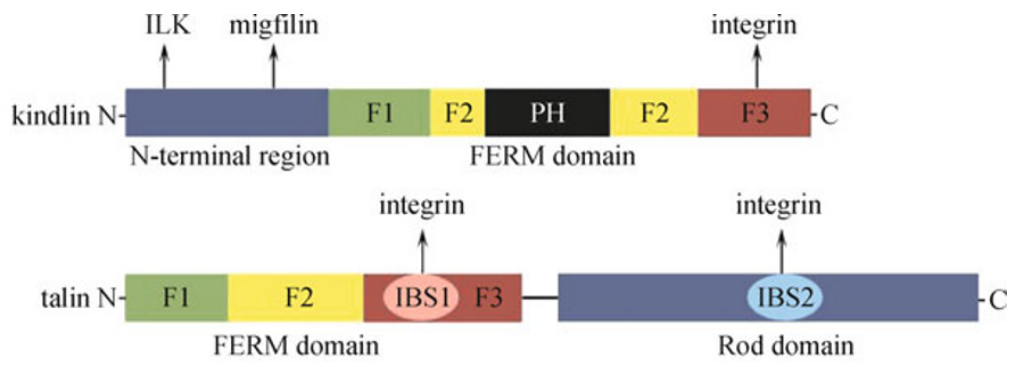

Figure 4. Schematic drawing of the domain architecture of the FERM domain in kindlins and talin (drawing not to scale). Talin and kindlins contain a FERM domain that shares high structural similarity and consists of three subdomains (F1, F2, and F3). A significant difference between the 2 FERM domains is that the F2 subdomain in kindlins is split by a Pleckstrin Homology $(\mathrm{PH}) \mathrm{motif}$. Arrows indicate the regions in kindlins and talin that interact with integrin $\beta$ subunits, ILK or migfilin.

For example, integrin $\alpha 5 \beta 1$, which interacts with its ligand fibronectin through an auxiliary binding site in addition to the canonical RGD site, has been shown to cycle between a relaxed (low affinity) and tensioned (high affinity) state in response to force generated by the cytoskeleton (Friedland et al., 2009). Interestingly, the binding interface in the relaxed state only included the RGD site of fibronectin, while in the tension state it also included the synergy site. Application of force thus switches the relaxed state, which relies on RGD recognition, to a new tension state with increased bond strength, involving both the RGD site and the synergy site, thus raising the question on whether synergy sites exist more broadly in integrin ligands. It also remains to be determined whether talin and kindlins are required in this force generated activation process, or whether in adherent cells, they function essentially during the process of integrin outside-in signaling.

\section{PERSPECTIVES}

The last two years have witnessed an explosion of new data that have now established a fairly comprehensive picture of the molecular events that lead to integrin allb $\beta 3$ activation in human platelets, or $\beta 2$ integrin activation in leukocytes. Some of these new data have been derived from the investigation of patients with rare genetic blood cell disorders, and underline the relevance for the identification and in-depth investigation of such patients. The recent data inevitably also raise numerous new questions. With the increasing number of proteins that directly interact with the short cytoplasmic tail of integrin $\beta$ subunits, it remains to be seen whether additional proteins are involved in integrin activation, or whether different activation states are regulated by different proteins. Also, the identified overlapping contact sites, such as those of talin IBS1 and talin IBS2 in the integrin $\beta$ subunit membrane proximal helix, or the binding sites that are in close proximity in the $\beta 3 \mathrm{C}$-terminal part, namely those of kindlin and Src, underline the need for further studies to elucidate whether these protein interactions are cooperative, competitive or sequential. Finally, posttranslational modifications, involving
$\mathrm{Y}$ or $\mathrm{S} / \mathrm{T}$ phosphorylation of the integrin cytoplasmic tail or phosphorylation of the binding partners are most likely of major importance in the fine-tuning of integrin activation and outside-in signaling.

\section{ACKNOWLEDGEMENTS}

The authors would like to thank Dr. Guoyu Meng for the computerdesigned structural model in Fig. 2B. This work was supported in part by grant No. 30710103905 from the National Natural Science Foundation of China, grant ANR-08-GENOPAT-028 from "Agence Nationale pour la Recherche," France, and funds from "Fondation BNP-Paribas," France.

\section{ABBREVIATIONS}

ABS, actin binding site; $\mathrm{CHO}$, Chinese hamster ovary; DAG, diacylglycerol; ECM, extracellular matrix; ESC, embryonic stem cell; FA, focal adhesions; FAK, focal adhesion kinase; FC, focal contacts; GPCR, G protein coupled receptor family; GT, Glanzmann's thrombasthenia; IBS, integrin binding site; ILK, integrin linked kinase; $L A D$, leukocyte adhesion deficiency; PAR, proteinase activated receptor; PKC, protein kinase C; PMA, phorbol 12-myristate 13acetate; PMN, polymorphonuclear granulocyte; PTB, phosphotyrtosine binding; RIAM, Rap1GTP-interacting adaptor molecular; VBS, vinculin binding site; SNP, single nucleotide polymorphism

\section{REFERENCES}

Abram, C.L., and Lowell, C.A. (2009). The ins and outs of leukocyte integrin signaling. Annu Rev Immunol 27, 339-362.

Anthis, N.J., Wegener, K.L., Ye, F., Kim, C., Goult, B.T., Lowe, E.D., Vakonakis, I., Bate, N., Critchley, D.R., Ginsberg, M.H., et al. (2009). The structure of an integrin/talin complex reveals the basis of inside-out signal transduction. EMBO J 28, 3623-3632.

Arias-Salgado, E.G., Lizano, S., Sarkar, S., Brugge, J.S., Ginsberg, M.H., and Shattil, S.J. (2003). Src kinase activation by direct interaction with the integrin beta cytoplasmic domain. Proc Natl Acad Sci U S A 100, 13298-13302.

Beckerle, M.C., Miller, D.E., Bertagnolli, M.E., and Locke, S.J. (1989). Activation-dependent redistribution of the adhesion plaque protein, talin, in intact human platelets. J Cell Biol 109, 3333-3346. 
Bergmeier, W., Goerge, T., Wang, H.W., Crittenden, J.R., Baldwin, A. C., Cifuni, S.M., Housman, D.E., Graybiel, A.M., and Wagner, D.D. (2007). Mice lacking the signaling molecule CalDAG-GEFI represent a model for leukocyte adhesion deficiency type III. J Clin Invest 117, 1699-1707.

Bouaouina, M., Lad, Y., and Calderwood, D.A. (2008). The N-terminal domains of talin cooperate with the phosphotyrosine binding-like domain to activate beta1 and beta3 integrins. J Biol Chem 283, 6118-6125.

Bunch, T.A. (2010). Integrin alphallbbeta3 activation in Chinese hamster ovary cells and platelets increases clustering rather than affinity. J Biol Chem 285, 1841-1849.

Calderwood, D.A., and Ginsberg, M.H. (2003). Talin forges the links between integrins and actin. Nat Cell Biol 5, 694-697.

Calderwood, D.A., Zent, R., Grant, R., Rees, D.J., Hynes, R.O., and Ginsberg, M.H. (1999). The Talin head domain binds to integrin beta subunit cytoplasmic tails and regulates integrin activation. J Biol Chem 274, 28071-28074.

Calderwood, D.A., Yan, B., de Pereda, J.M., Alvarez, B.G., Fujioka, Y., Liddington, R.C., and Ginsberg, M.H. (2002). The phosphotyrosine binding-like domain of talin activates integrins. J Biol Chem 277, 21749-21758.

Critchley, D.R. (2009). Biochemical and structural properties of the integrin-associated cytoskeletal protein talin. Annu Rev Biophys 38, 235-254.

Crittenden, J.R., Bergmeier, W., Zhang, Y., Piffath, C.L., Liang, Y., Wagner, D.D., Housman, D.E., and Graybiel, A.M. (2004). CalDAG-GEFI integrates signaling for platelet aggregation and thrombus formation. Nat Med 10, 982-986.

Dowling, J.J., Vreede, A.P., Kim, S., Golden, J., and Feldman, E.L. (2008). Kindlin-2 is required for myocyte elongation and is essential for myogenesis. BMC Cell Biol 9, 36.

Friedland, J.C., Lee, M.H., and Boettiger, D. (2009). Mechanically activated integrin switch controls alpha5beta1 function. Science 323, 642-644.

García-Alvarez, B., de Pereda, J.M., Calderwood, D.A., Ulmer, T.S., Critchley, D., Campbell, I.D., Ginsberg, M.H., and Liddington, R.C. (2003). Structural determinants of integrin recognition by talin. Mol Cell 11, 49-58.

Geiger, B., Spatz, J.P., and Bershadsky, A.D. (2009). Environmental sensing through focal adhesions. Nat Rev Mol Cell Biol 10, 21-33.

Gingras, A.R., Ziegler, W.H., Bobkov, A.A., Joyce, M.G., Fasci, D., Himmel, M., Rothemund, S., Ritter, A., Grossmann, J.G., Patel, B., et al. (2009). Structural determinants of integrin binding to the talin rod. J Biol Chem 284, 8866-8876.

Han, J., Lim, C.J., Watanabe, N., Soriani, A., Ratnikov, B., Calderwood, D.A., Puzon-McLaughlin, W., Lafuente, E.M., Boussiotis, V. A., Shattil, S.J., et al. (2006). Reconstructing and deconstructing agonist-induced activation of integrin alphallbbeta3. Curr Biol 16, 1796-1806.

Harburger, D.S., and Calderwood, D.A. (2009). Integrin signalling at a glance. J Cell Sci 122, 159-163.

Harburger, D.S., Bouaouina, M., and Calderwood, D.A. (2009). Kindlin-1 and -2 directly bind the $\mathrm{C}$-terminal region of beta integrin cytoplasmic tails and exert integrin-specific activation effects. J Biol Chem 284, 11485-11497.

Horwitz, A., Duggan, K., Buck, C., Beckerle, M.C., and Burridge, K. (1986). Interaction of plasma membrane fibronectin receptor with talin-a transmembrane linkage. Nature 320, 531-533.

Hughes, P.E., Diaz-Gonzalez, F., Leong, L., Wu, C., McDonald, J.A., Shattil, S.J., and Ginsberg, M.H. (1996). Breaking the integrin hinge. A defined structural constraint regulates integrin signaling. J Biol Chem 271, 6571-6574.

Hynes, R.O. (2002). Integrins: bidirectional, allosteric signaling machines. Cell 110, 673-687.

Kim, C., Lau, T.L., Ulmer, T.S., and Ginsberg, M.H. (2009). Interactions of platelet integrin alphallb and beta3 transmembrane domains in mammalian cell membranes and their role in integrin activation. Blood 113, 4747-4753.

Kinashi, T., Aker, M., Sokolovsky-Eisenberg, M., Grabovsky, V., Tanaka, C., Shamri, R., Feigelson, S., Etzioni, A., and Alon, R. (2004). LAD-III, a leukocyte adhesion deficiency syndrome associated with defective Rap1 activation and impaired stabilization of integrin bonds. Blood 103, 1033-1036.

Kindler, T. (1954). Congenital poikiloderma with traumatic bulla formation and progressive cutaneous atrophy. $\mathrm{Br} \mathrm{J}$ Dermatol 66 , 104-111.

Kloeker, S., Major, M.B., Calderwood, D.A., Ginsberg, M.H., Jones, D. A., and Beckerle, M.C. (2004). The Kindler syndrome protein is regulated by transforming growth factor-beta and involved in integrin-mediated adhesion. J Biol Chem 279, 6824-6833.

Krüger, M., Moser, M., Ussar, S., Thievessen, I., Luber, C.A., Forner, F., Schmidt, S., Zanivan, S., Fässler, R., and Mann, M. (2008). SILAC mouse for quantitative proteomics uncovers kindlin-3 as an essential factor for red blood cell function. Cell 134, 353-364.

Kuijpers, T.W., van de Vijver, E., Weterman, M.A., de Boer, M., Tool, A.T., van den Berg, T.K., Moser, M., Jakobs, M.E., Seeger, K., Sanal, O., et al. (2009). LAD-1/variant syndrome is caused by mutations in FERMT3. Blood 113, 4740-4746.

Larjava, H., Plow, E.F., and Wu, C. (2008). Kindlins: essential regulators of integrin signalling and cell-matrix adhesion. EMBO Rep 9, 1203-1208.

Lau, T.L., Kim, C., Ginsberg, M.H., and Ulmer, T.S. (2009). The structure of the integrin alphallbbeta3 transmembrane complex explains integrin transmembrane signalling. EMBO $\mathrm{J} \mathrm{28,}$ 1351-1361.

Lee, H.S., Lim, C.J., Puzon-McLaughlin, W., Shattil, S.J., and Ginsberg, M.H. (2009). RIAM activates integrins by linking talin to ras GTPase membrane-targeting sequences. J Biol Chem 284, 5119-5127.

Legate, K.R., Montañez, E., Kudlacek, O., and Fässler, R. (2006). ILK, PINCH and parvin: the tIPP of integrin signalling. Nat Rev Mol Cell Biol 7, 20-31.

Luo, B.H., Carman, C.V., and Springer, T.A. (2007). Structural basis of integrin regulation and signaling. Annu Rev Immunol 25, 619-647.

Ma, Y.Q., Qin, J., and Plow, E.F. (2007). Platelet integrin alpha(Ilb) beta(3): activation mechanisms. J Thromb Haemost 5, 1345 1352

Ma, Y.Q., Qin, J., Wu, C., and Plow, E.F. (2008). Kindlin-2 (Mig-2): a co-activator of beta3 integrins. J Cell Biol 181, 439-446.

Mackinnon, A.C., Qadota, H., Norman, K.R., Moerman, D.G., and Williams, B.D. (2002). C. elegans PAT-4/ILK functions as an adaptor protein within integrin adhesion complexes. Curr Biol 12, 787-797.

Moes, M., Rodius, S., Coleman, S.J., Monkley, S.J., Goormaghtigh, E., Tremuth, L., Kox, C., van der Holst, P.P., Critchley, D.R., and 
Kieffer, N. (2007). The integrin binding site 2 (IBS2) in the talin rod domain is essential for linking integrin beta subunits to the cytoskeleton. J Biol Chem 282, 17280-17288.

Montanez, E., Ussar, S., Schifferer, M., Bösl, M., Zent, R., Moser, M., and Fässler, R. (2008). Kindlin-2 controls bidirectional signaling of integrins. Genes Dev 22, 1325-1330.

Mory, A., Feigelson, S.W., Yarali, N., Kilic, S.S., Bayhan, G.I., Gershoni-Baruch, R., Etzioni, A., and Alon, R. (2008). Kindlin-3: a new gene involved in the pathogenesis of LAD-III. Blood 112, 2591.

Moser, M., Nieswandt, B., Ussar, S., Pozgajova, M., and Fässler, R. (2008). Kindlin-3 is essential for integrin activation and platelet aggregation. Nat Med 14, 325-330.

Moser, M., Bauer, M., Schmid, S., Ruppert, R., Schmidt, S., Sixt, M., Wang, H.V., Sperandio, M., and Fässler, R. (2009). Kindlin-3 is required for beta2 integrin-mediated leukocyte adhesion to endothelial cells. Nat Med 15, 300-305.

Nurden, A.T. (2006). Glanzmann thrombasthenia. Orphanet J Rare Dis 1, 10-20.

Pasvolsky, R., Feigelson, S.W., Kilic, S.S., Simon, A.J., Tal-Lapidot, G., Grabovsky, V., Crittenden, J.R., Amariglio, N., Safran, M., Graybiel, A.M., et al. (2007). A LAD-III syndrome is associated with defective expression of the Rap-1 activator CalDAG-GEFI in lymphocytes, neutrophils, and platelets. J Exp Med 204, 1571-1582.

Rivera, J., Lozano, M.L., Navarro-Núñez, L., and Vicente, V. (2009). Platelet receptors and signaling in the dynamics of thrombus formation. Haematologica 94, 700-711.

Rodius, S., Chaloin, O., Moes, M., Schaffner-Reckinger, E., Landrieu, I., Lippens, G., Lin, M., Zhang, J., and Kieffer, N. (2008). The talin rod IBS2 alpha-helix interacts with the beta3 integrin cytoplasmic tail membrane-proximal helix by establishing charge complementary salt bridges. J Biol Chem 283, 24212-24223.

Rogalski, T.M., Mullen, G.P., Gilbert, M.M., Williams, B.D., and Moerman, D.G. (2000). The UNC-112 gene in Caenorhabditis elegans encodes a novel component of cell-matrix adhesion structures required for integrin localization in the muscle cell membrane. J Cell Biol 150, 253-264.

Saltel, F., Mortier, E., Hytönen, V.P., Jacquier, M.C., Zimmermann, P., Vogel, V., Liu, W., and Wehrle-Haller, B. (2009). New PI(4,5)P2and membrane proximal integrin-binding motifs in the talin head control beta3-integrin clustering. J Cell Biol 187, 715-731.

Savage, B., Almus-Jacobs, F., and Ruggeri, Z.M. (1998). Specific synergy of multiple substrate-receptor interactions in platelet thrombus formation under flow. Cell 94, 657-666.

Shattil, S.J., Cunningham, M., and Hoxie, J.A. (1987). Detection of activated platelets in whole blood using activation-dependent monoclonal antibodies and flow cytometry. Blood 70, 307-315.

Shi, X., Ma, Y.Q., Tu, Y., Chen, K., Wu, S., Fukuda, K., Qin, J., Plow, E. F., and Wu, C. (2007). The MIG-2/integrin interaction strengthens cell-matrix adhesion and modulates cell motility. J Biol Chem 282, 20455-20466.

Shimaoka, M., Takagi, J., and Springer, T.A. (2002). Conformational regulation of integrin structure and function. Annu Rev Biophys Biomol Struct 31, 485-516.

Siegel, D.H., Ashton, G.H., Penagos, H.G., Lee, J.V., Feiler, H.S., Wilhelmsen, K.C., South, A.P., Smith, F.J., Prescott, A.R., Wessagowit, V., et al. (2003). Loss of kindlin-1, a human homolog of the Caenorhabditis elegans actin-extracellular-matrix linker protein UNC-112, causes Kindler syndrome. Am J Hum Genet 73, 174-187.

Su, X., Mi, J., Yan, J., Flevaris, P., Lu, Y., Liu, H., Ruan, Z., Wang, X., Kieffer, N., Chen, S., et al. (2008). RGT, a synthetic peptide corresponding to the integrin beta 3 cytoplasmic C-terminal sequence, selectively inhibits outside-in signaling in human platelets by disrupting the interaction of integrin alpha Ilb beta 3 with Src kinase. Blood 112, 592-602.

Svensson, L., Howarth, K., McDowall, A., Patzak, I., Evans, R., Ussar, S., Moser, M., Metin, A., Fried, M., Tomlinson, I., et al. (2009). Leukocyte adhesion deficiency-III is caused by mutations in KINDLIN3 affecting integrin activation. Nat Med 15, 306-312.

Tadokoro, S., Shattil, S.J., Eto, K., Tai, V., Liddington, R.C., de Pereda, J.M., Ginsberg, M.H., and Calderwood, D.A. (2003). Talin binding to integrin beta tails: a final common step in integrin activation. Science 302, 103-106.

Tanentzapf, G., and Brown, N.H. (2006). An interaction between integrin and the talin FERM domain mediates integrin activation but not linkage to the cytoskeleton. Nat Cell Biol 8, 601-606.

Tremuth, L., Kreis, S., Melchior, C., Hoebeke, J., Rondé, P., Plançon, S., Takeda, K., and Kieffer, N. (2004). A fluorescence cell biology approach to map the second integrin-binding site of talin to a 130amino acid sequence within the rod domain. J Biol Chem 279, 22258-22266.

Tu, Y., Wu, S., Shi, X., Chen, K., and Wu, C. (2003). Migfilin and Mig-2 link focal adhesions to filamin and the actin cytoskeleton and function in cell shape modulation. Cell 113, 37-47.

Ussar, S., Wang, H.V., Linder, S., Fässler, R., and Moser, M. (2006). The Kindlins: subcellular localization and expression during murine development. Exp Cell Res 312, 3142-3151.

Ussar, S., Moser, M., Widmaier, M., Rognoni, E., Harrer, C., GenzelBoroviczeny, O., Fässler, R., and van Heyningen, V. (2008). Loss of Kindlin-1 causes skin atrophy and lethal neonatal intestinal epithelial dysfunction. PLoS Genet 4, e1000289.

Vinogradova, O., Velyvis, A., Velyviene, A., Hu, B., Haas, T., Plow, E., and Qin, J. (2002). A structural mechanism of integrin alpha(Illb) beta(3) "inside-out" activation as regulated by its cytoplasmic face. Cell 110, 587-597.

Watanabe, N., Bodin, L., Pandey, M., Krause, M., Coughlin, S., Boussiotis, V.A., Ginsberg, M.H., and Shattil, S.J. (2008). Mechanisms and consequences of agonist-induced talin recruitment to platelet integrin alphallbbeta3. J Cell Biol 181, 1211-1222.

Wegener, K.L., Partridge, A.W., Han, J., Pickford, A.R., Liddington, R. C., Ginsberg, M.H., and Campbell, I.D. (2007). Structural basis of integrin activation by talin. Cell 128, 171-182.

Weinstein, E.J., Bourner, M., Head, R., Zakeri, H., Bauer, C., and Mazzarella, R. (2003). URP1: a member of a novel family of PH and FERM domain-containing membrane-associated proteins is significantly over-expressed in lung and colon carcinomas. Biochim Biophys Acta 1637, 207-216.

Wu, C. (2005). Migfilin and its binding partners: from cell biology to human diseases. J Cell Sci 118, 659-664.

Xiong, J.P., Stehle, T., Diefenbach, B., Zhang, R., Dunker, R., Scott, D.L., Joachimiak, A., Goodman, S.L., and Arnaout, M.A. (2001). Crystal structure of the extracellular segment of integrin alpha Vbeta3. Science 294, 339-345.

Xiong, J.P., Stehle, T., Goodman, S.L., and Arnaout, M.A. (2003). 
New insights into the structural basis of integrin activation. Blood 102, 1155-1159.

Ye, F., Hu, G., Taylor, D., Ratnikov, B., Bobkov, A.A., McLean, M.A., Sligar, S.G., Taylor, K.A., and Ginsberg, M.H. (2010). Recreation of the terminal events in physiological integrin activation. J Cell Biol
188, 157-173.

Zhu, J., Luo, B.H., Barth, P., Schonbrun, J., Baker, D., and Springer, T. A. (2009). The structure of a receptor with two associating transmembrane domains on the cell surface: integrin alphallbbeta3. Mol Cell 34, 234-249. 